\title{
DEFORMABILITY AND QUANTITATIVE DESCRIPTION OF THE MICROSTRUCTURE OF HOT-DEFORMED IN 718 SUPERALLOY
}

\author{
${ }^{1}$ Kazimierz DUCKI, ${ }^{1}$ Jacek MENDALA, 'Lilianna WOJTYNEK \\ ${ }^{1}$ Silesian University of Technology, Katowice, Poland, EU, \\ kazimierz.ducki@polsl.pl, jacek.mendala@polsl.pl \\ 2Opole University of Technology, Opole, Poland, EU, \\ l.wojtynek@po.opole.pl
}

https://doi.org/10.37904/metal.2019.809

\begin{abstract}
The influence of initial soaking and parameters of hot plastic working on the deformability and microstructure of the IN 718 superalloy have been presented. The research was performed on a torsion plastometer in the range of temperatures of $900-1,150{ }^{\circ} \mathrm{C}$, at a strain rates of $0.1 \mathrm{~s}^{-1}$ and $1.0 \mathrm{~s}^{-1}$. Plastic properties of the alloy were characterized by the worked out flow curves and the temperature relationships of flow stress and strain limit. The structural inspections were performed on microsections taken from plastometric samples after socalled "freezing". The stereological parameters as the recrystallized grain size, inhomogenity and grain shape have been determined. Functional relation between the Zener-Hollomon parameter and the average grain area has been developed and the activation energy for hot working has been estimated.
\end{abstract}

Keywords: IN 718 superalloy, hot deformation, recrystallization, quantitative metallography, Zener-Hollomon parameter

\section{INTRODUCTION}

The behaviour of metals and alloys during hot plastic working has a complex nature and it varies with the changing of such process parameters as [1,2]: deformation, strain rate and temperature. The high-temperature plastic deformation is coupled with dynamic recovery and recrystallization processes which influencing the microstructure and properties of steels and alloys.

The Ni-based superalloys are difficult to deform and are characterized by high values of flow stress at a high temperature. High deformation resistance of superalloys is caused by a complex phase composition, high activation energy for hot working and a low rate of dynamic recrystallization. When choosing the conditions for hot plastic working of Ni-based superalloys, the following factors should be considered $[3,4]$ : the matrix grain size, plastic deformation parameters and the course of the recrystallization process. The grain size is particular importance. Grain refining leads to an increased rate of recovery and dynamic recrystallization and to a smaller diameter of recrystallized grains. This is important, for the grain refinement in a Ni-based superalloys has an advantageous influence on increasing their yield point and fatigue strength $[5,6]$.

In the presented study, research has been undertaken on the influence of initial soaking and the parameters of hot plastic working on the deformability and microstructure in the IN 718 superalloy.

\section{MATERIAL AND EXPERIMENTAL PROCEDURE}

The examinations were performed on rolled bars, $16 \mathrm{~mm}$ in diameter, of the IN 718 superalloy. The chemical composition is given in Table 1.

The samples for investigations were made from rolled bars sections which were subjected to preheating, i.e. $1,120{ }^{\circ} \mathrm{C} / 2 \mathrm{~h}$ with subsequent cooling in water. Heat treatment of this type corresponds to the soaking parameters of the investigated superalloy before hot plastic processing $[7,8]$. 
Table 1 Chemical composition of the investigated IN 718 superalloy

\begin{tabular}{|c|c|c|c|c|c|c|c|c|c|c|c|c|c|c|}
\hline \multicolumn{10}{|c|}{ Content of an element (wt. \%) } \\
\hline $\mathrm{C}$ & $\mathrm{Si}$ & $\mathrm{Mn}$ & $\mathrm{P}$ & $\mathrm{S}$ & $\mathrm{Cr}$ & $\mathrm{Ni}$ & $\mathrm{Mo}$ & $\mathrm{Co}$ & $\mathrm{Al}$ & $\mathrm{Cu}$ & $\mathrm{Nb}$ & $\mathrm{Ti}$ & $\mathrm{B}$ & $\mathrm{Fe}$ \\
\hline 0.04 & 0.16 & 0.08 & 0.007 & 0.002 & 18.5 & 52.1 & 3.05 & 0.24 & 0.54 & 0.03 & 4.89 & 0.91 & 0.001 & 19.45 \\
\hline
\end{tabular}

The research on the alloy deformability was performed in a hot torsion test on a Setaram torsion plastometer 7 MNG. The plastometric tests were performed every $50^{\circ} \mathrm{C}$ in a temperature range of $900-1,150{ }^{\circ} \mathrm{C}$, with a constant holding time of 10 minutes at the defined temperature. Solid cylindrical specimens $(\varnothing 6.0 \times 50 \mathrm{~mm})$ were twisted at a rotational speed of 50 and $500 \mathrm{rpm}$, which corresponds to the strain rate of $0.1 \mathrm{~s}^{-1}$ and $1.0 \mathrm{~s}^{-1}$, respectively. To freeze the structure, the specimens after deformation until failure were cooled in water.

From the data recorded, dependencies were determined of the flow stress $\left(\sigma_{p}\right)$ as a function of substitute strain $(\varepsilon)$, according to the methodology presented in papers $[9,10]$. On the flow curves determined, the following parameters characterizing plastic properties of the alloy in the torsion test were defined:

- $\sigma_{p p}$ - maximum flow stress on the flow curve;

- $\quad \varepsilon_{p}$ - deformation corresponding to the maximum flow stress;

- $\sigma_{f}$ - stress at which the sample is subject to failure;

- $\quad \varepsilon_{f}$ - deformation at which the sample is subject to failure, the so-called strain limit.

Relations between the flow stress and alloy deformation, and the deformation conditions were described using the Zener-Hollomon parameter $Z\left(\mathrm{~s}^{-1}\right)[11,12]$ :

$$
Z=\dot{\varepsilon} \exp \left(\frac{Q}{R \cdot T}\right)=A \cdot\left[\sinh \left(\alpha \cdot \sigma_{p p}\right)\right]^{n}
$$

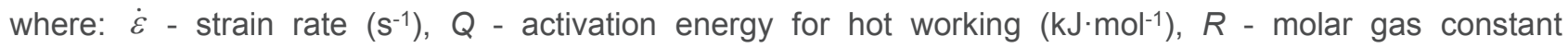
$\left(8,314 \mathrm{~J} \cdot \mathrm{mol}^{-1} \cdot \mathrm{K}^{-1}\right), T$ - temperature $(\mathrm{K})$, and $A\left(\mathrm{~s}^{-1}\right), \alpha\left(\mathrm{MPa}^{-1}\right), n(-)$ - constants depending on grade of the investigated material.

The activation energy for hot working $Q$ was determined in accordance with the procedure specified in the work by Schindler and Bořuta [13]. The solution algorithm consisted in transforming Eq. (1) to the form:

$$
\dot{\varepsilon}=A \exp \left(\frac{-Q}{R T}\right) \cdot\left[\sinh \left(\alpha \cdot \sigma_{p p}\right)\right]^{n}
$$

Further procedure was based on solving Eq. (2) by a graphic method with using the regression analysis.

Structural inspections were performed on longitudinal microsections taken from the plastically deformed samples until failure after so-called "freezing". Due to the deformation inhomogeneity, microscopic observation was conducted in a representative region located at a distance of ca. $0.65-0.75$ of the specimen radius. A quantitative analysis of the investigated microstructures was carried out by means of a computer program MET-ILO v. 3.0 [14]. For the analyzed microstructures, in accordance with the methodology presented in paper [15], the following stereological parameters were determined:

- $\quad$ average area of grain plane section $(\bar{A})$;

- $\quad$ variability coefficient of the grain plane section area $v(\bar{A})$;

- $\quad$ volume fraction of dynamically recrystallized grains in the structure $V_{v}$;

- $\quad$ grain elongation coefficient $\delta$ (Feret coefficient);

- classical dimensionless shape coefficient $\xi$. 


\section{RESULTS AND DISCUSSION}

The results of the plastometric investigations, in the form of the calculated alloy flow curves at temparatures of $900-1,150{ }^{\circ} \mathrm{C}$ along with corresponding specimen microstructures for two strain rates, are shown in Figure 1 and Figure 2. The curves obtained for the strain rate of $0.1 \mathrm{~s}^{-1}$ have a shape characteristic of a material in which dynamic recovery and recrystallization took place (see Figure 1). High deformability values $\left(\varepsilon_{f}=2.4-3.2\right)$ were obtained for the alloy in a wide range of torsion temperature, i.e. $1,000-1,100{ }^{\circ} \mathrm{C}$. After deformation at temperature range of $900-1,000{ }^{\circ} \mathrm{C}$, the alloy microstructure is fully recrystallized and are characterized by significant fine-grained (Figures 1a-c). With an increasing torsion temperature range of $1,050-1,150^{\circ} \mathrm{C}$, a gradual growth of the recrystallized grains were observed (Figures $1 \mathbf{d}$-f). The recrystallized grains are characterized by a deformed grain boundary line, which indicates an extensive cumulated deformation in the specimens.
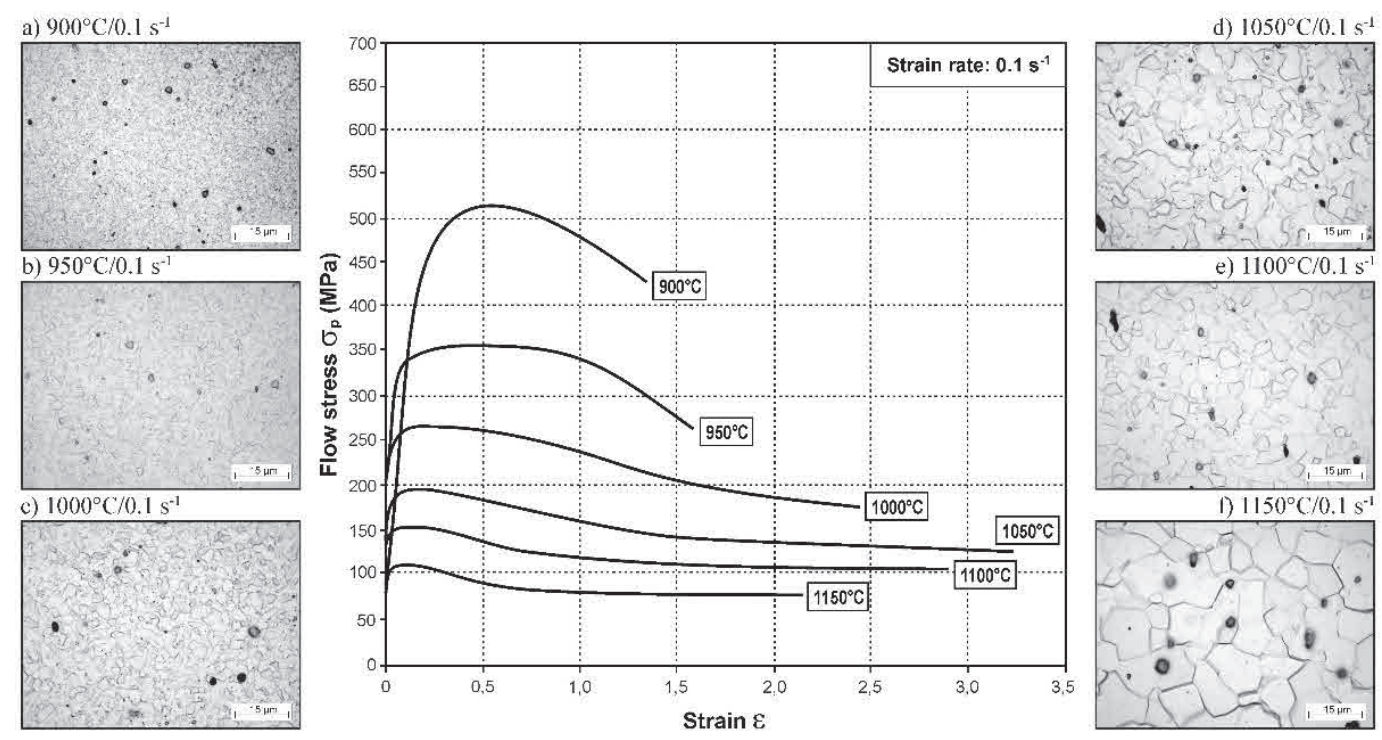

Figure 1 The effect of deformation temperature on the flow stress and microstructure of the IN 718 superalloy after initial soaking at $1,120{ }^{\circ} \mathrm{C} / 2 \mathrm{~h}$. Strain rate: $0.1 \mathrm{~s}^{-1}$
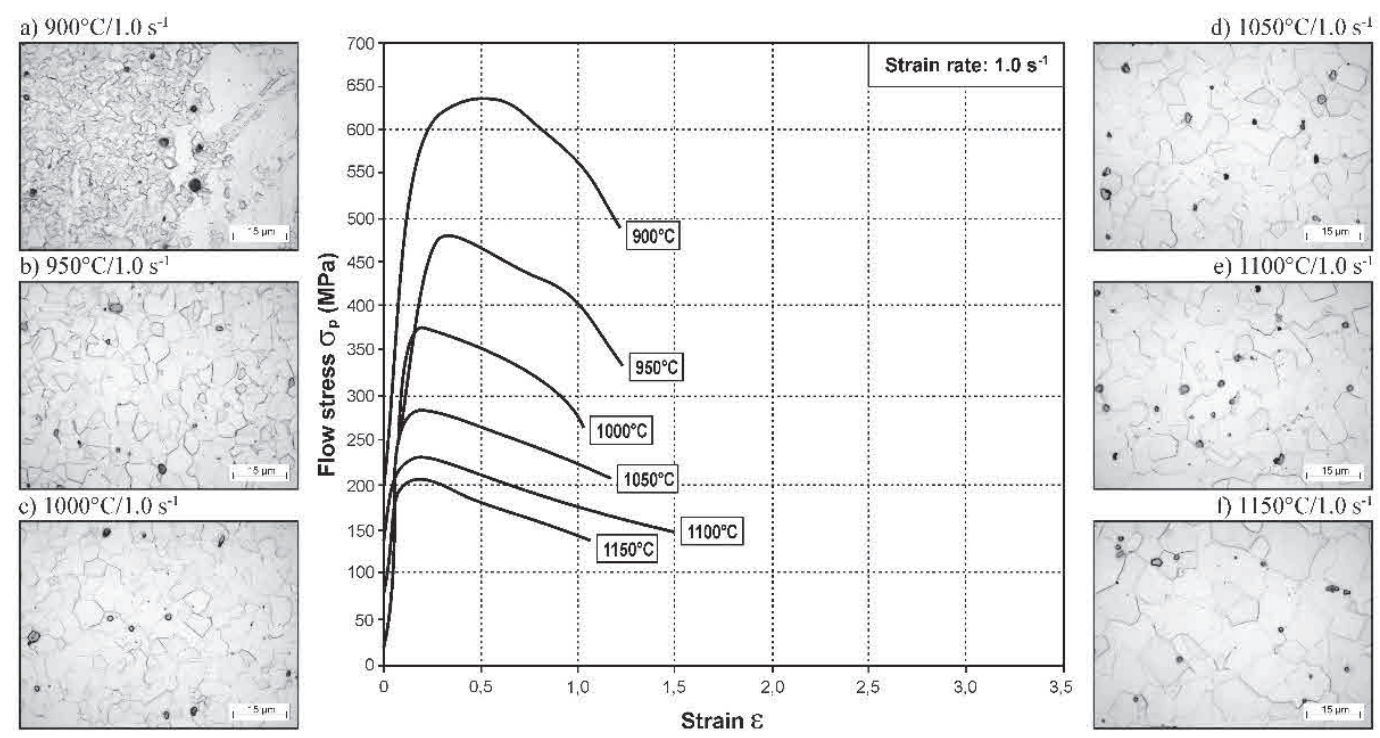

Figure 2 The effect of deformation temperature on the flow stress and microstructure of the IN 718 superalloy after initial soaking at $1,120^{\circ} \mathrm{C} / 2 \mathrm{~h}$. Strain rate: $1.0 \mathrm{~s}^{-1}$ 
An increase of strain rate to $1.0 \mathrm{~s}^{-1}$ significantly increases the flow stress values and clearly decreases the alloy deformability at all the temperatures examined (Figure 2). This phenomenon can be explained by a higher alloy consolidation rate as well as too slow removal of the strengthening as a result of dynamic recovery and recrystallization. The highest values of strain limit were lower $\left(\varepsilon_{f}=1.2-1.5\right)$ and they were obtained for the alloy in a narrow range of torsion temparatures, i.e. $1,050-1,100{ }^{\circ} \mathrm{C}$. After deformation at $900{ }^{\circ} \mathrm{C}$, the alloy microstructure is not completely recrystallized, which is indicated by the presence of primary elongated grains and fine recrystallized grains (Figure 2a). At a torsion temperatures range of $950-1150{ }^{\circ} \mathrm{C}$, the alloy structure consisted of dynamically recrystallized grains (Figures $\mathbf{2 b - f}$ ). With an increasing deformation temperature, a gradual growth of the recrystallized grains was observed. The boundaries of recrystallized grains are less deformed compared to the specimens deformed at a lower rate, which can be explained by a lower cumulated deformation in the specimens.

The results of a quantitative evaluation of the investigated IN 718 superalloy microstructure after deformation until failure in a temperature range of $900-1,150{ }^{\circ} \mathrm{C}$ and a strain rate of $0.1 \mathrm{~s}^{-1}$ and $1.0 \mathrm{~s}^{-1}$ are presented in Table 2 and in Figure 3 and Figure 4.

Table 2 Stereological parameters of the IN 718 superalloy microstructure after deformation in a temperature range of $900-1,150{ }^{\circ} \mathrm{C}$ at a strain rates of $0.1 \mathrm{~s}^{-1}$ and $1.0 \mathrm{~s}^{-1}$

\begin{tabular}{|c|c|c|c|c|c|c|c|c|}
\hline \multicolumn{2}{|c|}{$\begin{array}{l}\text { Deformation } \\
\text { parameters }\end{array}$} & \multirow{2}{*}{$\begin{array}{c}\begin{array}{l}\text { Volume fraction of } \\
\text { recrystallized grains }\end{array} \\
\begin{array}{c}V_{\mathrm{v}} \\
(\%)\end{array}\end{array}$} & \multicolumn{2}{|c|}{$\begin{array}{c}\text { Grain average } \\
\text { area }\end{array}$} & \multicolumn{2}{|c|}{$\begin{array}{c}\text { Grain elongation } \\
\text { coefficient }\end{array}$} & \multicolumn{2}{|c|}{$\begin{array}{c}\text { Dimensionless } \\
\text { shape coefficient }\end{array}$} \\
\hline $\begin{array}{c}\mathrm{T} \\
\left({ }^{\circ} \mathrm{C}\right)\end{array}$ & $\begin{array}{c}\dot{\varepsilon} \\
\left(\mathbf{s}^{-1}\right)\end{array}$ & & $\underset{\left(\mu \mathrm{m}^{2}\right)}{\bar{A}}$ & $\begin{array}{l}v(\bar{A}) \\
(\%)\end{array}$ & $\delta$ & $\begin{array}{l}v(\delta) \\
(\%)\end{array}$ & $\xi$ & $\begin{array}{l}v(\xi) \\
(\%)\end{array}$ \\
\hline 900 & 0.1 & 100 & 4.3 & 174 & 1.65 & 32 & 0.68 & 23 \\
\hline 950 & 0.1 & 100 & 6.2 & 176 & 1.69 & 32 & 0.69 & 24 \\
\hline 1000 & 0.1 & 100 & 19.5 & 180 & 1.68 & 29 & 0.81 & 21 \\
\hline 1050 & 0.1 & 100 & 36.5 & 123 & 1.70 & 30 & 0.78 & 23 \\
\hline 1100 & 0.1 & 100 & 78.2 & 90 & 1.69 & 30 & 0.69 & 28 \\
\hline 1150 & 0.1 & 100 & 204.9 & 82 & 1.85 & 59 & 0.70 & 21 \\
\hline 900 & 1.0 & 59 & $21.4^{*}$ & 288 & 1.64 & 24 & 0.79 & 21 \\
\hline 950 & 1.0 & 100 & 49.2 & 97 & 1.69 & 39 & 0.76 & 20 \\
\hline 1000 & 1.0 & 100 & 65.4 & 94 & 1.68 & 30 & 0.76 & 21 \\
\hline 1050 & 1.0 & 100 & 91.0 & 95 & 1.79 & 52 & 0.75 & 19 \\
\hline 1100 & 1.0 & 100 & 141.5 & 109 & 1.82 & 43 & 0.71 & 21 \\
\hline 1150 & 1.0 & 100 & 207.4 & 110 & 1.85 & 50 & 0.70 & 20 \\
\hline
\end{tabular}

In the microstructure of the IN 718 superalloy after deformation in the investigated temperature range at a rate equal $0.1 \mathrm{~s}^{-1}$, monotonous growth of the grain average area $(\bar{A})$ is observed from a value $4.3 \mu \mathrm{m}^{2}$ at $900{ }^{\circ} \mathrm{C}$ to $204.9 \mu \mathrm{m}^{2}$ at $1,150^{\circ} \mathrm{C}$ (Figure 3). Up to the deformation temperature of $1,150^{\circ} \mathrm{C}$, the dynamically recrystallized grains are elongated $(\delta=1.65-1.85)$ - see Figure 4 . An increase of the torsion rate up to $1.0 \mathrm{~s}^{-1}$ induces a clear growth of the recrystallized grain size. Also, in this case, in the investigated range of deformation temperatures, a monotonous growth of the grain average area $(\bar{A})$ was observed, from $21.4 \mu \mathrm{m}^{2}$ at $900{ }^{\circ} \mathrm{C}$ to $207.4 \mu \mathrm{m}^{2}$ at $1,150{ }^{\circ} \mathrm{C}$ (Figure 3). In the analyzed range of torsion temperatures of $900-1,150{ }^{\circ} \mathrm{C}$, the dynamically recrystallized grains are also elongated $(\delta=1.64-1.85)$ - see Figure 4. Based on the obtained results, should be noted that higher strain rate provide shorter time for the energy accumulation and lower mobility boundaries which contribute in the nucleation and growth of dynamically recrystallized grains. For this 
reason with deformation at $0.1 \mathrm{~s}^{-1}$ more and more potential nuclei are activated and new recrystalized grains appear, which are smaller than grains obtained during deformation at $1.0 \mathrm{~s}^{-1}$.

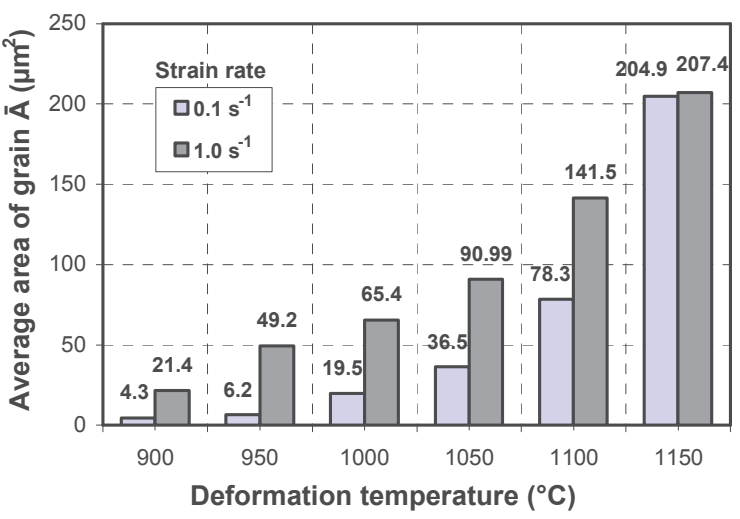

Figure 3 The effect of deformation temperature on the average area of recrystallized grain after torsion at a rate of $0.1 \mathrm{~s}^{-1}$ and $1.0 \mathrm{~s}^{-1}$

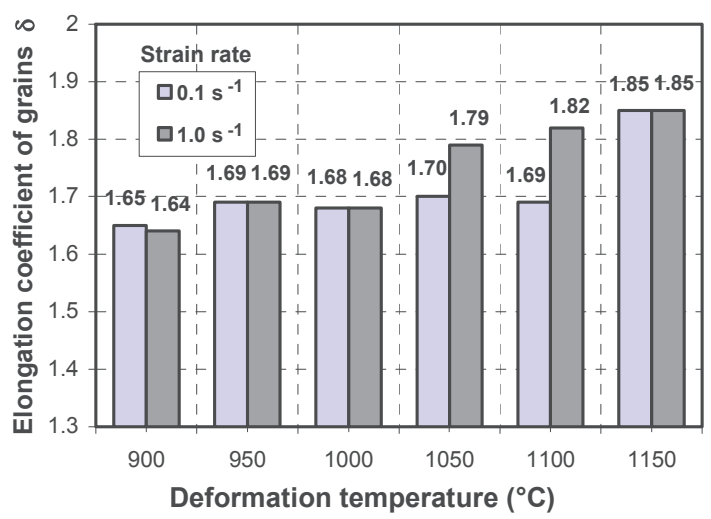

Figure 4 The effect of deformation temperature on the elongation coefficient of recrystallized grain after torsion at a rate of $0.1 \mathrm{~s}^{-1}$ and $1.0 \mathrm{~s}^{-1}$

The dependencies between the IN 718 superalloy deformation parameters and the average area of the recrystallized grains are shown in Figure 5. For both of the torsion rates applied, mathematical dependencies of an exponential nature were obtained.

The functional dependence between the average grain area and the Zener-Hollomon parameter $Z$ are presented in Figure 6. For the analyzed IN 718 superalloy deformation parameters, a mathematical dependence of an involutory nature was determined:

$\bar{A}=1.77 \times 10^{6} \times Z^{-0.243}$

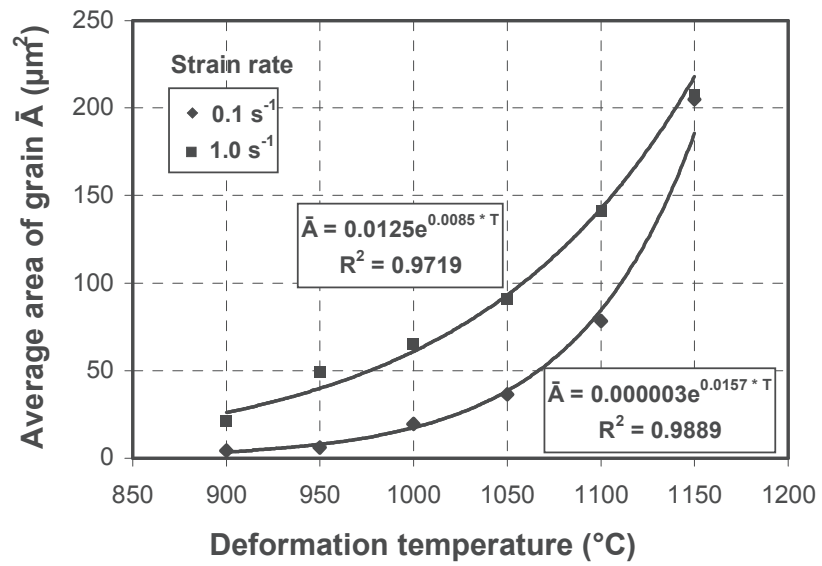

Figure 5 Relationship between the average grain area after recrystallization versus deformation temperature and strain rate

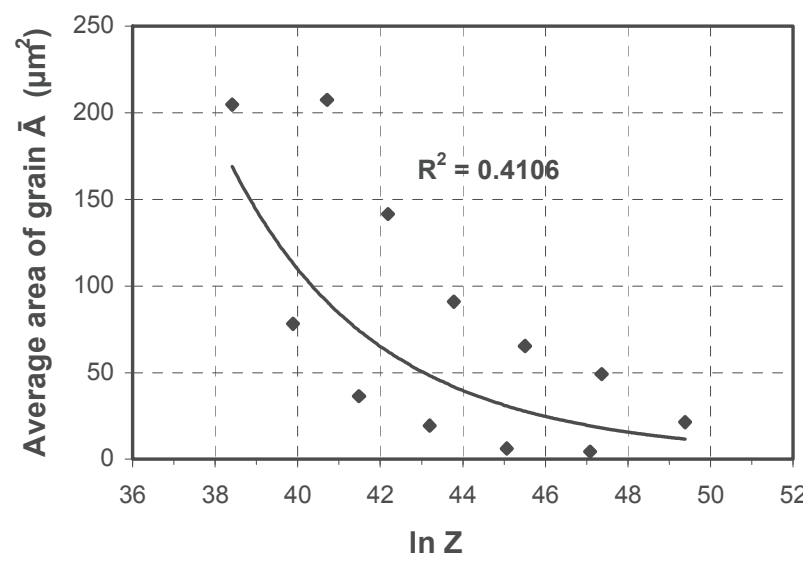

Figure 6 Relationship between the average grain area after recrystallization and the Zener-Hollomon parameter Z

The activation energy for hot working $Q$ was calculated by the means of a computer programme Energy 3.0 [13]. The estimated activation energy for hot working in the range of the applied deformation temperatures of $900-1,150{ }^{\circ} \mathrm{C}$ and strain limits $0.1 \mathrm{~s}^{-1}$ and $1.0 \mathrm{~s}^{-1}$, was high and amounted $Q=478.6 \mathrm{~kJ} \cdot \mathrm{mol}^{-1}$. 


\section{CONCLUSION}

The performed examinations on a torsion plastometer in the range temperature of $900-1,150{ }^{\circ} \mathrm{C}$ and strain rate $0.1 \mathrm{~s}^{-1}$ and $1.0 \mathrm{~s}^{-1}$, indicated that the deformability and microstructure of the IN 718 superalloy depend considerably on parameters of the hot plastic working.

Optimum values of maximum flow stress and strain limit were obtained for the superalloy after the initial soaking at $1120{ }^{\circ} \mathrm{C} / 2 \mathrm{~h}$ and deformation in the temperature range of $1,000-1,100{ }^{\circ} \mathrm{C}$ at strain rate $0.1 \mathrm{~s}^{-1}$. The use of higher deformation temperature and strain rate $1.0 \mathrm{~s}^{-1}$ is not recommended due to a growth of matrix grain, difficulties in the course of the recrystallization process as well as a decrease of the alloy plasticity.

A considerable influence has been found of the deformation temperature and strain rate on grain size and inhomogenity of the grain size after dynamic recrystallization. It was found that with an increasing deformation temperature and strain rate, a gradual growth of the recrystallized grains was observed.

The functional dependence between the average grain area $(\bar{A})$ and the Zener-Hollomon parameter $(Z)$ has been described by an involutory function in the form of equation (3).

\section{REFERENCES}

[1] ZHOU, L. X. and BAKER, T. N. Effects of strain rate and temperature on deformation behaviour of IN 718 during high temperature deformation. Materials Science and Engineering. 1994. vol. A177, pp. 1-9.

[2] McQUEEN, H.J. and RYAN, N.D. Constitutive analysis in hot working. Materials Science and Engineering. 2002. vol. A322, pp. 43-63.

[3] KOUL, A.K., IMMARIGEON, J.P. and WALLACE, W. Microstructural control in Ni-base superalloy. In: Advanced in high temperature structural materials and protective coatings. Ottawa: National Research Council, 1994, pp. 95-125.

[4] DUCKI, K.J. and RODAK, K. The hot-deformability and quantitative description of the microstructure of hotdeformed Fe-Ni superalloy. IOP Conference Series - Materials Science Engineering. 2011. vol. 22, Article Number: 012011.

[5] HÄRKEGÅRD, G. and GUÉDOU, J.Y. Disc materials for advanced gas turbines. In: Proc. of the $6^{\text {th }}$ Liege Conference: Materials for Advanced Power Engineering. Liege, 1998, pp. 913-931.

[6] DUCKI, K.J. Research of the microstructure and precipitation strengthening in a high-temperature Fe-Ni superalloy. IOP Conference Series - Materials Science Engineering. 2012. vol. 35, Article Number: 012007.

[7] STOLOFF, N.S. Wrought and P/M superalloys. In ASM Handbook, vol. 1: Properties and selection iron, steels and high-performance alloys. ASM International, USA, 2005, pp. 1478-1527.

[8] DUCKI, K., PŁACHTA, A., MENDALA, J. and WOJTYNEK, L. The characteristic of deformability of Ni-Fe superalloy during high-temperature deformation. In: METAL 2017: 26th International Conference on Metallurgy and Materials. Ostrava: TANGER, 2017, pp. 414-420.

[9] HADASIK, E. and SCHINDLER, I. Plasticity of metallic materials. Gliwice: Silesian University of Technology, House of Publishing, 2004, p. 246.

[10] HADASIK, E. Methodology for determination of the technological plasticity characteristics by hot torsion test. Archives of Metallurgy and Materials. 2005. vol. 50, pp. 729-746.

[11] ZENER, C. and HOLLOMON, J.H. Plastic flow and rupture of metals. Trans. of the ASM. 1944. vol. 33, pp. 163235.

[12] SELLARS, C.M. and TEGART, W.J. Hot workability. International Metallurgical Reviews. 1972. vol. 17, pp. 1-24.

[13] SCHINDLER, I. and BOŘUTA, J. Utilization Potentialities of the Torsion Plastometer. Katowice: Department of Mechanics and Metal Forming, Silesian University of Technology, 1998, p. 106.

[14] SZALA, J. Computer Program Quantitative Metallography: MET-ILO v. 3.0, Silesian University of Technology, 1997 (unpublished).

[15] CWAJNA, J., MALIŃSKI, M. and SZALA, J. The grain size as the structural criterion of the polycrystal quality evaluation. Materials Engineering. 1993. vol. 14, pp. 79-88. 